\title{
Thyroid and COVID-19: a review on pathophysiological, clinical and organizational aspects
}

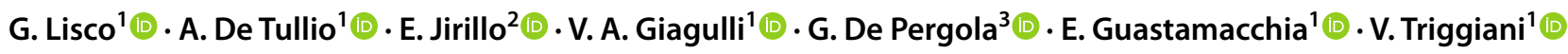

Received: 22 December 2020 / Accepted: 10 March 2021 / Published online: 25 March 2021

(c) The Author(s) 2021

\begin{abstract}
Background Thyroid dysfunction has been observed in patients with COVID-19, and endocrinologists are requested to understand this clinical issue. Pandemic-related restrictions and reorganization of healthcare services may affect thyroid disease management.

Objective and methods To analyze and discuss the relationship between COVID-19 and thyroid diseases from several perspectives. PubMed/MEDLINE, Google Scholar, Scopus, ClinicalTrial.gov were searched for this purpose by using free text words and medical subject headings as follows: "sars cov 2", "covid 19", "subacute thyroiditis", "atypical thyroiditis", "chronic thyroiditis", "hashimoto's thyroiditis", "graves' disease", "thyroid nodule", "differentiated thyroid cancer", "medullary thyroid cancer", "methimazole", "levothyroxine", "multikinase inhibitor", "remdesivir", "tocilizumab". Data were collected, analyzed, and discussed to answer the following clinical questions: "What evidence suggests that COVID-19 may induce detrimental consequences on thyroid function?"; "Could previous or concomitant thyroid diseases deteriorate the prognosis of COVID-19 once the infection has occurred?"; "Could medical management of thyroid diseases influence the clinical course of COVID-19?"; "Does medical management of COVID-19 interfere with thyroid function?"; "Are there defined strategies to better manage endocrine diseases despite restrictive measures and in-hospital and ambulatory activities reorganizations?".

Results SARS-CoV-2 may induce thyroid dysfunction that is usually reversible, including subclinical and atypical thyroiditis. Patients with baseline thyroid diseases are not at higher risk of contracting or transmitting SARS-CoV-2, and baseline thyroid dysfunction does not foster a worse progression of COVID-19. However, it is unclear whether low levels of free triiodothyronine, observed in seriously ill patients with COVID-19, may worsen the disease's clinical progression and, consequently, if triiodothyronine supplementation could be a tool for reducing this burden. Glucocorticoids and heparin may affect thyroid hormone secretion and measurement, respectively, leading to possible misdiagnosis of thyroid dysfunction in severe cases of COVID-19. High-risk thyroid nodules require a fine-needle aspiration without relevant delay, whereas other non-urgent diagnostic procedures and therapeutic interventions should be postponed.

Discussion Currently, we know that SARS-CoV-2 could lead to short-term and reversible thyroid dysfunction, but thyroid diseases seem not to affect the progression of COVID-19. Adequate management of patients with thyroid diseases remains essential during the pandemic, but it could be compromised because of healthcare service restrictions. Endocrine care centers should continuously recognize and classify priority cases for in-person visits and therapeutic procedures. Telemedicine may be a useful tool for managing patients not requiring in-person visits.
\end{abstract}

Keywords SARS-CoV-2 · COVID-19 - Subclinical thyroiditis · Chronic lymphocytic thyroiditis · Hypothyroidism · Hyperthyroidism · Graves' disease · Thyroid nodules · Pandemic

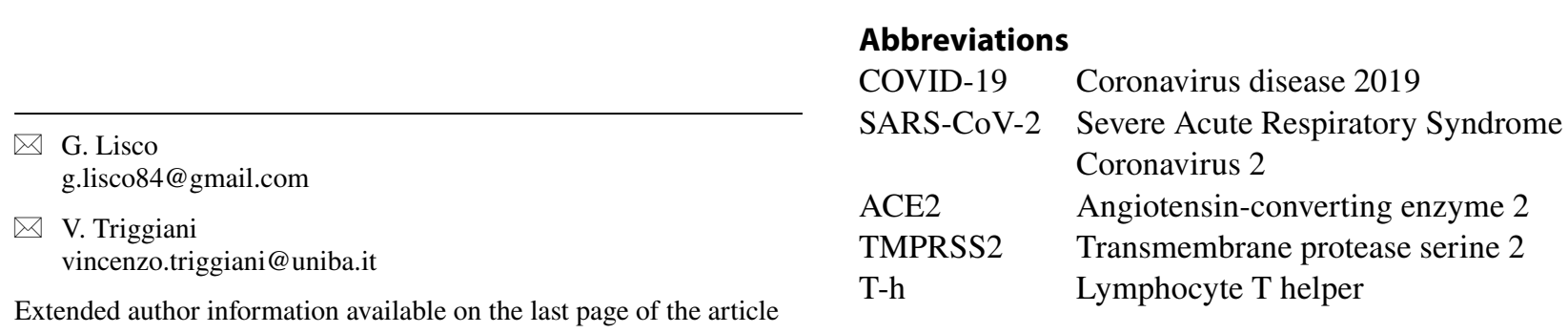




$\begin{array}{ll}\text { IL-6 } & \text { Interleukin-6 } \\ \text { TNF } & \text { Tumor necrosis factor } \\ \text { IFN } & \text { Interferon } \\ \text { fT4 } & \text { Free levothyroxine } \\ \text { fT3 } & \text { Free triiodothyronine } \\ \text { TSH } & \text { Thyroid-Stimulating Hormone } \\ \text { HT } & \text { Hashimoto's thyroiditis } \\ \text { GD } & \text { Graves' disease } \\ \text { ATDs } & \text { Antithyroid drugs } \\ \text { VD } & \text { Vitamin D } \\ \text { RDV } & \text { Remdesivir }\end{array}$

\section{Background}

Coronavirus disease 2019 (COVID-19) is a highly transmissible infectious disease caused by the Severe Acute Respiratory Syndrome Virus 2 (SARS-CoV-2), a positive-sense, single strand, enveloped RNA virus belonging to the family of beta-coronaviruses [1, 2]. The disease rapidly spread, leading the World Health Organization General-Director Doctor Tedros Adhanom Ghebreyesus to state the ongoing COVID-19 pandemic on March 11, 2020 [3], when 118,000 worldwide confirmed cases were detected in 114 different nations. In most cases, SARS-CoV-2 infection occurs with mild-to-moderate symptoms [4], but a harmful clinical progression has been described in older men and those with underlying comorbidities [5-9]. COVID-19 was found to affect several organs and systems [10], including the endocrine system $[11,12]$ with possible short and long-term consequences [13]. For instance, the pituitary-thyroid axis should be considered a susceptible target of SARS-CoV-2, and a direct or indirect pituitary injury has been described as a determining factor of possible secondary hypothyroidism (functional or organic) [14]. In line with these suggestions, thyroid dysfunction could be observed during and after a COVID-19 infection, and, therefore, it is expected that some new-onset or recurrent thyroid dysfunctions could be attributable to a recent SARS-CoV-2 infection. Moreover, a preexisting or new-onset thyroid hormone imbalance, such as the low T3 syndrome, could be associated with the disease severity in COVID-19 [15]. On the other hand, healthcare services have been reorganized, and access to healthcare facilities is restricted to dealing with epidemiological difficulties. As a consequence, thyroid disease management may be potentially affected. Given these assumptions, the authors emphasized some clinical questions related to thyroid diseases/dysfunctions and COVID-19. A point-topoint discussion was carried-out focusing on pre-specified clinical queries as follows: "What evidence suggests that COVID-19 may induce detrimental consequences on thyroid function?"; "Could previous or concomitant thyroid diseases deteriorate the prognosis of COVID-19 once the infection has occurred?"; "Could medical management of thyroid diseases influence the clinical course of COVID19?"; "Does medical management of COVID-19 interfere with thyroid function?"; "Are there defined strategies to better manage endocrine diseases despite restrictive measures and in-hospital and ambulatory activities reorganizations?". For this purpose, PubMed/MEDLINE, Google Scholar, Scopus, ClinicalTrial.gov were searched by using free text words and medical subject headings related to "sars cov 2", "covid 19", "subacute thyroiditis", "atypical thyroiditis", "chronic thyroiditis", "hashimoto's thyroiditis", "graves' disease", "thyroid nodule", "differentiated thyroid cancer", "medullary thyroid cancer", "methimazole", "levothyroxine", "multikinase inhibitor", "remdesivir", "tocilizumab". Case reports, original articles, randomized controlled trials, reviews, and meta-analysis written in English were analyzed, selected, and discussed.

\section{Results}

\section{Biochemical and immunological relationship between SARS-CoV-2 and thyroid gland}

Angiotensin-converting enzyme 2 (ACE2) and transmembrane protease serine 2 (TMPRSS2) are essentially involved in SARS-CoV-2 internalization into host cells playing a relevant role in the pathogenesis of COVID-19 in several species, including humans [16]. These receptors are expressed on a broad range of tissue. The highest levels of ACE2 expression and activity were found at the small intestine, kidney, heart, salivary glands, testicles, and thyroid, whereas lower levels were observed in the brain, skin, pituitary, and skeletal muscles $[17,18]$. Thyroid follicular cells express ACE2 as suggested by direct molecular analysis of surgical samples of thyroid tissue [19], leading the gland to be susceptible to SARS-CoV-2 injury once the infection has occurred. In this clinical setting, thyroid damage could result from either a direct or immune-mediated injury [20] (Fig. 1). Integrin $\alpha v \beta 3$ is known to recognize and bind ArgGly-Asp (RGD) and Lys-Gly-Asp (KGD) motifs localized into the molecular structure of both ACE2 and spike protein of SARS-CoV and SARS-CoV-2, possibly playing a role in antagonizing SARS-CoV-2 binding to ACE2 and consequently reducing SARS-CoV-2 entry into host cells [21]. Since SARS-CoV-2 may alternatively interact with integrin $\alpha v \beta 3$, Sigrist et al. hypothesized that this binding might facilitate SARS-CoV-2 internalization into host cells as an alternative pathway respective to ACE2 [22]. According to this point of view, another pathophysiological scenario may have prospected. Indeed, thyroid hormones may bind the integrin receptors on the cell surface, thus, activating signal 


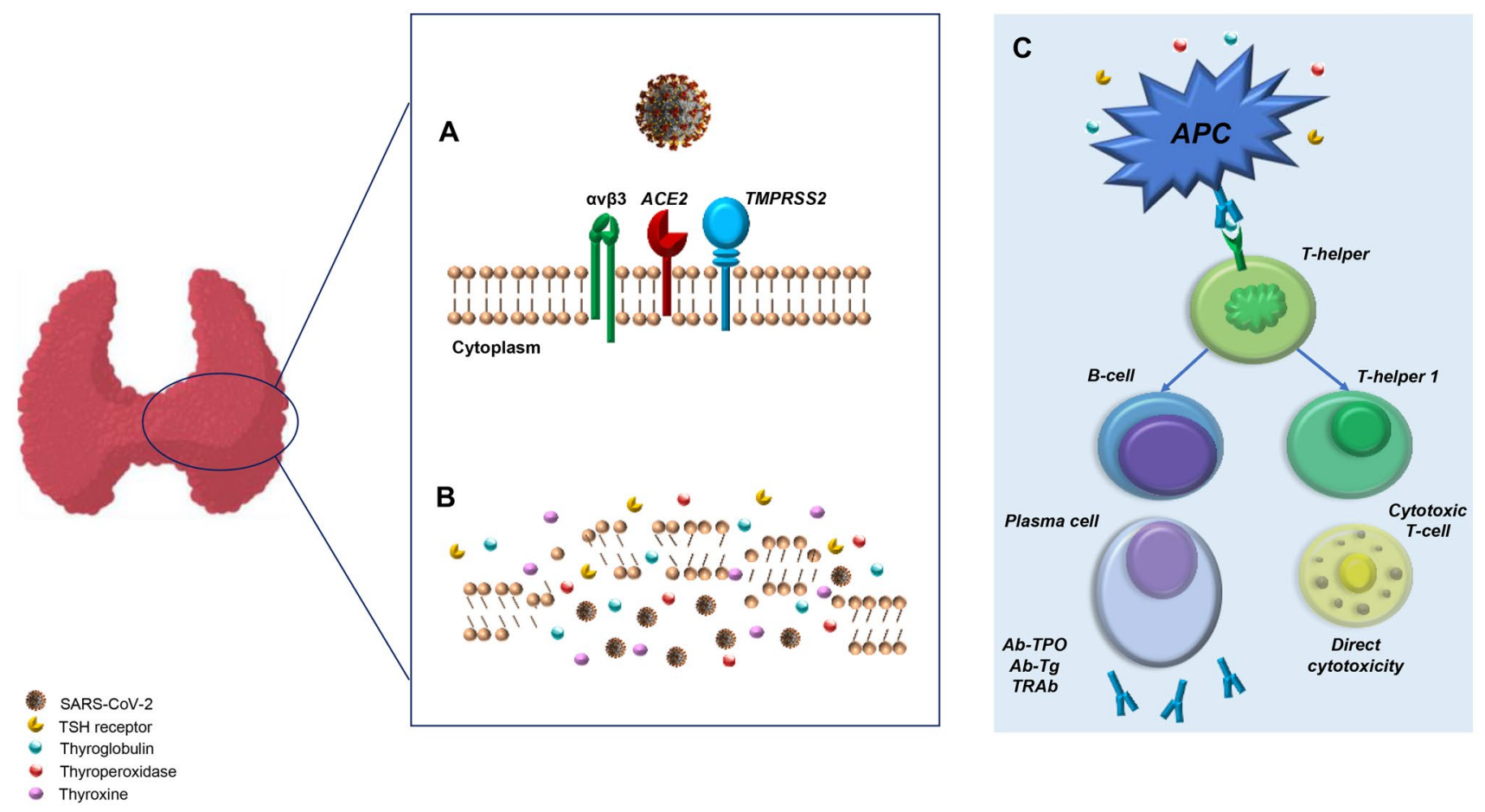

Fig. 1 Simplified mechanism of thyroid injury in COVID-19. a SARS-CoV-2 internalization into thyrocyte; b viral shedding with systemic spread of viral progeny, thyroxine, thyroglobulin, thyroperoxidase, and TSH receptor (acute and subacute thyroiditis); c

pathways inside the cell and regulating the transcription of genes involved in anti-apoptotic, angiogenetic properties, and ultimately, supporting cell proliferation [23]. There is evidence that levothyroxine could foster chemo- and radioresistance and the progression of some thyroid malignancy by activating a second pathway, namely via integrin $\alpha v \beta 3$ $[24,25]$. Furthermore, levothyroxine may increase the expression of integrin $\alpha v \beta 3$ on the cell surface; therefore, T4 may enhance to a more extent SARS-CoV-2 internalization, possibly worsening the prognosis in case of COVID-19 [26]. However, this hypothesis should be confirmed before making conclusions.

Immune response pathways in COVID-19 have recently been reviewed, showing a relevant role of $\mathrm{CD} 4+$ and $\mathrm{CD} 8+\mathrm{T}$ cells by targeting different targets of SARS-CoV-2 to contrast the infection while persisting in the resolution phase of the disease [27]. Additionally, an increase in T-helper (h) 17 and a lower T-regulatory-to-T-h 17 ratio related to high serum levels of interleukin (IL)- 6 may contribute to an exaggerated cytokine release, frequently observed in patients with a severe form of the disease [28]. Several cytokines and chemokines, such as IL-1 beta, IL-2, IL-4, IL-6, IL-8, IL-17, IL-22, Tumor Necrosis Factor (TNF) alpha, interferon (IFN) gamma, granulocyte colony-stimulating factor, IFN-gamma induced protein 10 and monocyte immune-processing of thyroid antigens by antigen-presenting cells (APCs) and consequent activation (in predisposed individuals) of autoreactive lymphocytes (Hashimoto's thyroiditis, Graves' disease)

chemoattractant protein 1 , might additionally play a role in the pathogenesis of COVID-19, especially for the severe form of the disease [29-34]. Given such an immune system imbalance, patients with thyroid autoimmune diseases might undergo a worse clinical course of COVID-19 due to higher baseline levels of serum IL-6 and TNF alpha compared to healthy individuals. On the other hand, SARS-CoV-2 may break immunotolerance in predisposed patients, leading to new onset of immune-mediated thyroiditis, exacerbating a previous thyroid disease, or inducing a recurrence [35-37].

\section{What evidence suggests that COVID-19 may induce detrimental consequences on thyroid function?}

As previously demonstrated for SARS-CoV, also SARSCoV-2 may lead to thyroid dysfunction [38]. In March 2020, the first case of subacute thyroiditis diagnosed in an 18-yearold woman has been described [39]. The patient was admitted to the hospital with typical signs and symptoms of viral thyroiditis occurring 15 days after a SARS-CoV-2-positive oropharyngeal swab within the context of a mild COVID-19 case [39]. After that, several other cases have been reported worldwide [40-42]. Subacute thyroiditis symptoms occurred 16-36 days after the resolution of COVID-19 [43, 44]. A 
prompt response to oral prednisone usually occurs, and euthyroidism returns after a few weeks of treatment [44-46].

A cases of Hashimoto's thyroiditis (HT) with subclinical hypothyroidism in a 45-year-old Chinese man [47] and a myxedema coma in a 69-year-old woman fatality-case have also been described [48]. Thyroid autoimmunity was certainly a pre-existing and undiagnosed condition, but SARSCoV-2 probably exacerbated the basal condition in these patients. Persistent hypothyroidism, mostly due to HT, has been described in $7 \%$ of severe acute respiratory syndrome coronavirus survivors and these data suggest that coronaviruses may have a potential for inducing long-term thyroid dysfunction [49]. In a cohort of 191 mild-to-moderate confirmed COVID-19 cases, thyroid dysfunction has been observed in around $15 \%$ of them [50]. Patients with subnormal TSH levels compared to those with normal TSH levels $(0.21 \mathrm{mUI} / \mathrm{L}$ vs. $1.2 \mathrm{mUI} / \mathrm{L})$ had a more frequent fever $(89$ vs. $59 \%$, p 0.03 ) and a lower SARS-Cov-2 cycle threshold value at polymerase chain reaction ( 20.9 vs. 26.3 , p 0.01 ) suggestive to a higher viral load [50]. In another retrospective study among 50 confirmed COVID-19 patients, more than half of them (56\%) had transiently subnormal TSH levels, and those with lower TSH values had poor prognosis [51]. The prevalence of thyroid autoimmunity appeared to be similar or slighter higher [50,52] than the general population $[53,54]$. Considering that autoimmune conditions have been associated to SARS-CoV-2 infection [55], and that viral infection have demonstrated to trigger autoimmune thyroiditis [56], it remains unclear whether thyroid dysfunction occurring in COVID-19 patients could be related to thyroid autoimmunity.

The relationship between severe COVID-19 and the low T3 syndrome is mostly attributable to systemic inflammation [57]. It should be considered that high levels of IL-6 are related to a poorer prognosis of COVID-19 patients, mostly due to a much extent of respiratory involvement [58-60]. IL-6 seems to suppress the production of free levothyroxine (fT4) and free triiodothyronine (fT3) and is implicated in the pathogenesis of the low T3 syndrome [61, 62]. Muller et al. analyzed thyroid dysfunction in critically ill patients in relation to the presence or absence of COVID-19 by comparing hospitalized patients' data of 2019 to 2020 [52]. After excluding baseline thyroid dysfunction, the results showed lower serum TSH concentration, and higher C-reactive protein levels in COVID-19 (2020) than non-COVID-19 (2019) patients [52]. Moreover, serum fT4 levels were higher, and fT3 were similar in COVID-19 than non-COVID-19 critically ill individuals due to a possible overlapping between a low T3 syndrome and thyroxine toxicosis, attributable to a painless (atypical) subacute thyroiditis [52].

In a retrospective study assessing the prevalence of thyroid dysfunction in confirmed COVID-19 cases, the prevalence of thyrotoxicosis and hypothyroidism was found in
$20 \%$ and 5\%, respectively [63]. Thyrotoxicosis was associated with a more significant hospital stay and a higher in-hospital mortality rate [63]. IL-6 was inversely related to TSH levels, and consequently, thyrotoxicosis resulted in higher concentrations of IL-6 (OR 3.25) [63]. Conversely, fT3 levels appeared to be inversely related to the severity of systemic inflammation [49]. In most cases, the TSH and fT3 levels dropped during the acute phase and remained low during convalescence, but in another longitudinal observational study recruiting 456 patients ( 334 were admitted to hospital for COVID-19), $86.6 \%$ of them were euthyroid, and no cases of overt thyrotoxicosis were diagnosed [64]. TSH and fT4 concentrations at admission were lower than baseline but normalized during the convalescence. A possible drop in TSH levels could be attributable to a blunt pituitary secretion of the thyrotropin due to either a direct and indirect pituitary injury related to SARS-CoV-2 [14, 64]. Altogether these results suggest that thyroid dysfunction may occur, transiently, in COVID-19 patients and could be related to the severity of inflammation. Specific trials are required to clarify the long-term consequences of SARS-CoV-2 infection on thyroid function.

\section{Could previous or concomitant thyroid diseases deteriorate the prognosis of COVID-19 once the infection has occurred?}

A meta-analysis of 8 observational studies found that the frequency of thyroid diseases was higher in COVID-19 patients with poorer prognosis (HR 2.48) [37]; however, some limitations may have affected the result, including study selection methods and a restricted number of cases. The role of hypothyroidism as a possible risk factor for poor prognosis in COVID-19 patients has been investigated more in detail in a retrospective study from New York City [65]. Data were collected from an electronic medical database that included patients with a laboratory-confirmed COVID-19 on a nasopharyngeal swab. Among 3,703 COVID-19 positive patients, 251 (6.8\%) had pre-existing hypothyroidism, including those who had received a diagnosis of hypothyroidism and those on levothyroxine treatment. Patients with hypothyroidism compared to those without hypothyroidism were more frequently female ( 69 vs. $43 \%, p<0.001$ ), mostly non-Hispanic white (45 vs. $26 \%, p<0.001$ ), and had more than two underlying comorbidities, such as overweight-obesity syndrome, arterial hypertension, and diabetes mellitus (68 vs. $53 \%, p<0.001$ ). Despite these differences, a preexisting hypothyroidism per se was found not to affect the prognosis of COVID-19 [65] even if further investigation needed to evaluate this risk concerning the baseline levels of hypothyroidism control (i.e., TSH and fT4).

A strict relationship between the severity of systemic inflammation, particularly IL-6, and hyperthyroidism was 
found, and COVID-19 patients with hyperthyroidism and thyrotoxicosis displayed poor prognosis and more extended hospital stay compared to euthyroid patients [63]. IL-6 may induce either the onset or relapse of hyperthyroidism in GD as reported in two case reports [66], and GD relapse cases have been described in convalescent patients, too [67]. Although GD per se does not increase the risk of contracting COVID-19, SARS-CoV-2 infection in GD may disrupt the euthyroidism and make necessary a prompt recognition of hyperthyroidism recurrent/relapse to limit burdens [65]. Uncontrolled hyperthyroidism leads to adverse cardiovascular effects, including cardiac arrhythmias, hemodynamic instability, myocardial ischemia [69], and rises oxidative stress [70], and promotes hypercoagulative-hypofibrinolytic balance [71].

Despite patients with head and neck malignancies had a great chance of poor prognosis in the case of COVID-19, this relationship is still not completely understood for those with thyroid cancer [72]. Surgery and post-surgery phases are known to increase stress, possibly eliciting the pituitaryadrenal axis and catecholamine releases with a consequent and passing suppression of the immune system. Nonetheless, these pathophysiological changes should not be considered risk factors for contracting SARS-CoV-2 or developing a severe clinical progression once infected [72].

\section{Could medical management of thyroid diseases influence the clinical course of COVID-19?}

In seriously ill COVID-19 patients, serum fT3 concentrations were lower than expected and independently predicted all-cause mortality in this cluster of patients [73]. The low T3 syndrome is commonly observed in several acute and chronic clinical conditions such as in sepsis [74], myocardial infarction [75], and chronic heart failure [76, 77], and is the result of an adaptive mechanism whose severity is related to the levels of systemic inflammation [78], serum circulating cortisol, and disturbance of peripheral thyroid hormone transport and metabolism [79]. Normal circulating T3 levels are essential to maintain myocardial tropism [80] and antiinflammatory effects by reducing peripheral immune cells' recruitment and attenuating the immune system hyperactivation in response to endotoxemia [81]. T3 also reduces macrophage responsiveness to IL-6, suggesting a potential role of T3 replacement in contrasting an exaggerated systemic inflammation, innate immune response, and ultimately cytokine storm [82]. According to this point of view, the low T3 syndrome per se may affect the prognosis of COVID-19 [83] patients as similarly observed in other clinical scenarios [84-87]. The results of phase II, multicenter, prospective, randomized, double-blind, placebo-controlled trial would clarify the effects of T3 replacement in this setting [88].
Patients with thyroid disorders are equally at risk of contracting the infection as the general population; therefore, a subset of them would be affected by COVID-19 and should be managed according to the disease's clinical progression. The remaining are likely to be constrained by healthcare services' restrictions for coping with epidemiological conditions. It is necessary to ensure adequate access to cure and satisfactory monitoring methods at a distance. Liothyronine is currently approved to treat hypothyroidism and myxedema coma (intravenously) [89]. Despite a rationale for clinical use in selected cases, either alone or combined with levothyroxine [90], T3 replacement therapy has some drawbacks, including pharmacodynamic and pharmacokinetic characteristics and possible adverse effects, primarily on the cardiovascular system. Oral levothyroxine is a handy and safe medication for replacing hypothyroidism regardless of etiology, and antithyroid medications (ATDs) remain the favored treatment of new-onset hyperthyroidism, especially in GD [91]. A long-term low-dose ATDs therapy is a valuable alternative to radioiodine or thyroidectomy in patients with a persistent or recurrent disease [92], considering pandemic-related limitations [93]. A block and replace regimen could be more appropriate to avoid frequent thyroid function assessments and recurrent in-person visits for therapy adjustments [93]. Agranulocytosis, a rare but serious adverse event, usually occurs within three months after the start of treatment, and the risk is dose-dependent for methimazole (usually $>25-30 \mathrm{mg} /$ day) but not propylthiouracil [94]. In case of signs and symptoms of infection (i.e., respiratory) suggestive for agranulocytosis, a white blood cell count should be promptly obtained, and ATDs should be withdrawn for restoring normal white blood cell count [94]. The management of this complication could be critical because of possible symptoms of misinterpretation (fever, pharyngodynia), and restricted access to healthcare facilities for consultation, diagnosis, and alternative cure.

Target therapies, including multikinase inhibitors and mammalian target of rapamycin inhibitors, have a role in treating advanced thyroid cancers [95-100]. Some kinase inhibitors, including sorafenib, sunitinib, and vandetanib, were used against other viral agents, including coronaviruses, and their efficacy as therapeutic instruments in COVID-19 are currently under investigation [101]. On the other hand, the management of some cancer therapeutics may be a challenge during the pandemic considering possible adverse effects that may foster an undesirable progression of COVID-19 [102]. Reports about the safety and efficacy of multikinase inhibitors for treating advanced thyroid malignancies during the COVID-19 pandemic are currently lacking. Convincing conclusions are difficult to formulate, and starting, continuing, or withdrawing these medications should be carefully personalized possibly after an adequate 
consultation within a multidisciplinary team for a better assessment of the risk-benefit ratio [68].

\section{Does medical management of COVID-19 interfere with thyroid function?}

The milestones of treatment of COVID-19 remain the targeting of virus and host response by using different strategies, such as antivirals, monoclonal antibodies, antiinflammatory agents, immune-modulative target therapies [103]. According to the disease's severity [104], different therapeutic approaches are required aiming to reduce the length of transmissibility and the severity of symptoms [105]. As an example, circulatory and ventilatory support and anti-thrombotic therapy could be necessary for seriously ill patients [103]. Bamlanivimab [106] and Casirivimab/ Imdevimab [107], neutralizing monoclonal antibodies targeting SARS-CoV-2 spike protein and consequently tackling viral internalization into host's cells, received the approval for clinical use in patients tested positive within ten days and with a mild or even moderate COVID-19 symptoms, but at higher risk of disease progression due to underlying comorbidities or advanced age. Other clinical trials are currently ongoing in order to investigate the role of several medications for preventing the infection or improving the prognosis of COVID-19 in different clinical scenarios, such as vitamin D (NCT04535791 [108]; NCT04366908 [109]), ascorbic acid (NCT04264533) [110], hydroxychloroquine (NCT04590274) [111]. Some antiviral therapies received approval for emergency use against SARS-CoV-2 or may have a rationale considering their mechanisms of action, including interference with viral internalization (i.e., Umifenovir [112]); RNA-polymerase inhibition (Ribavirin [113], Remdesivir [114]); protease inhibition, including p3-chymotrypsin-like protease (i.e., Favipiravir [115]; Lopinavir/Ritonavir [116]; Sofosbuvir/daclatasvir [117]). These medications have been demonstrated to reduce hospital stay, and accelerate recovery time from disease, especially in moderate cases; however, their efficacy in severe cases could be significantly different according to the results of different trials $[118,119]$. Lopinavir and ritonavir may accelerate the metabolism of levothyroxine, diminishing levothyroxine's therapeutic effect [120-122].

Since the critical role of IL-6 in severe pulmonary injury in COVID-19 [123], humanized monoclonal antibodies targeting the IL-6 receptor subunit alpha may have a therapeutic role [124]. For example, tocilizumab reduced mechanical ventilation risk in inpatients with COVID-19, even if the mortality rate remains high in this setting [125]. Baricitinib is an inhibitor of the Janus kinase-signal transducer and activator of transcription proteins or JAK-STAT pathway that mediates cytokines or growth factors receptor signaling
[126]. Baricitinib suppresses the production of type 1 IFNs by dendritic cells and IL-6 from B cells [127]. In a doubleblind, randomized, placebo-controlled trial, patients on Baricitinib plus RDV recovered faster than those on RDV plus placebo [128]. Baricitinib, administered for atopic dermatitis, did not induce adverse thyroid events [129]; however, it remains unclear whether the possible onset of thyroid autoimmunity would be attributable to an underlying autoimmune condition than the consequence of an adverse event [130].

Dexamethasone at $6 \mathrm{mg} /$ day (for ten consecutive days) either orally or intravenously administered as an add-on to the standard of care versus standard of care alone demonstrated to reduce the 28 -day mortality rate by $17 \%$, more evidently in patients requiring invasive mechanical ventilation $(-36 \%)$ and in those on supplemental oxygen $(-18 \%)$ [131]. Cumulative data suggested that corticosteroids may be beneficial when administered in critically ill patients [132]. Glucocorticoids interfere with thyroid hormone metabolism at several levels, such as by blocking the peripheral conversion of T4 [133], and impair TSH secretion in a dosedependent manner [134]. In one observation, a single dose of dexamethasone $8 \mathrm{mg}$ administered intravenously reduced the TSH and fT3 levels by 8 to $47 \mathrm{~h}$ after the administration [135]. A high-dose dexamethasone regimen $(8 \mathrm{mg} / \mathrm{day}$ per 3 consecutive days) decreased baseline T3 serum levels without inhibiting T3 response to TSH stimulation [136]. On the other side, the glucocorticoid metabolism may be enhanced in hyperthyroidism and reduced in hypothyroidism, and circulating thyroxine levels may affect cortisol transport and bioavailability being inversely related to cortisol binding protein concentrations [137]. Furthermore, hyperthyroidism fosters albumin synthesis and secretion, and the contrary is observed in hypothyroidism [138]. Considering that albumin regulates dexamethasone distribution and bioavailability, thyroid dysfunction may affect dexamethasone pharmacokinetic influencing this variable [139].

To date, the mechanism of the so-called COVID-19 coagulopathy is well known and represents a combination of localized pulmonary platelet consumption, low-grade intravascular coagulation and thrombotic microangiopathy, endothelial dysfunction, and systemic inflammation [140]. Coagulopathy was found to be the result of both systemic inflammation and SARS-CoV-2 specific-mechanism via ACE2 inhibition, endothelial injury, and dysfunction, induction of autoimmunity [141]. Low-molecular-weight heparin could play a role in thromboprophylaxis, specifically in severe and seriously ill patients, even if further investigations are needed to clarify this topic [142]. Apart from the anticoagulative effects, low-molecular-weight heparin may induce additional effects, such as direct inhibition of viral entry into host cells by interacting with SARS-CoV-2 spike 
proteins; inhibition of heparanase activity, hence limiting vascular leakage; neutralization of the biological effect of cytokines; interference with leukocyte trafficking [143]. Fractionated and unfractionated heparin displace thyroid hormone from binding proteins, consequently affecting the measurement of both fT4 and fT3 with different assay platforms, such as equilibrium dialysis, ultracentrifugation, and direct immunoassay [144]. Therefore, thyroid hormones should be interpreted cautiously in patients on low molecular weight heparin for avoiding misdiagnosis.

\section{Are there defined strategies to better manage endocrine diseases despite restrictive measures and in-hospital and ambulatory activities reorganizations?}

During the pandemic, several in-hospital and ambulatory activities have been primarily reorganized, restricted, or even suspended to deal with local epidemiological conditions. The number of thyroid fine-needle aspiration procedures was constrained because of healthcare service restrictions [145]. Thus, the incidence of thyroid carcinomas could be underestimated with potentially detrimental consequences, especially for aggressive malignancies [146]. Strategies of possible management of thyroid diseases during the pandemic are necessary to avoid diagnostic and therapeutic delays in severe diseases and postpone safely deferrable non-urgent visits [147]. Fine needle aspiration with cytological assessment should be carried out in patients with high-risk thyroid nodules without relevant delays [145]. Furthermore, patients requiring surgery for thyroid malignancy should undergo an adequate clinical assessment to prioritize interventions that cannot be postponed [148, 149]. Besides clinical aspects, the management of these patients should also be scheduled considering the local transmission rate of COVID-19 and hospital resources [146]. Based upon these assumptions, a proposed endocrine surgery triaging algorithm aligned with the American College of Surgeons has been proposed. All endocrine surgeries could be deferred in case of a rise in transmission rate, except acute airway urgency [150]. French guidelines recommend managing thyroid surgery by scheduling the interventions as follows: urgent; requiring surgery as soon as possible; semi-urgent (surgery should be performed during the acute phase of the pandemic); highpriority elective surgery (surgery soon after the pandemic crisis); distant elective surgery (surgery should be postponed safely) [151]. For example, a thyroid carcinoma without aggressive histology but with overt signs and symptoms of local aggressiveness should be treated as a semi-urgent condition. Conversely, patients with thyroid carcinoma with a tumor size $>2 \mathrm{~cm}$ or those with lymph nodes involvement regardless of the primary neoplasm dimension should be scheduled for a high-priority elective surgery. Uncontrolled hyperthyroidism and benign goiter with manifest compressive symptoms should be scheduled for a semi-urgent surgery [151]. On the other side, surgery for low-risk papillary carcinomas may be postponed safely, and a "wait and see" approach should be preferred in this clinical setting.

Follow-up visits in cases of papillary thyroid cancer with an excellent or indeterminate prognosis may be postponed, according to epidemiological complaints, for a post-operative neck ultrasound. Patients could also be managed through telemedicine [72], as a valuable strategy for improving the standard of care in endocrinology during the pandemic [152], also guaranteeing reasonable patient satisfaction despite restrictions [153]. Social media messaging, email service, telephone consultations, and, where available, virtual digital visits could be considered reliable for educational purposes and to ensure a regular follow-up in patients with stable diseases. Laboratory tests may be sent to endocrine care centers periodically by emails or messages, and clinicians verify treatment effectiveness and carry-out minor therapy adjustments. A phone call may also manage minor medical consultations or explanations, while a virtual digital visit may be a useful tool for direct interaction with patients to assess and prioritize cases requiring in-person evaluation according to the medical history.

Nuclear medicine procedures declined remarkably during the lockdown as the consequences of both restrictive measures to contain the spread of the COVID-19 and risk of transmission among healthcare personnel [154]. For patients, radioactive iodine therapy exerts only mild effects on the immune system and should be administered safely in high-risk differentiated thyroid carcinomas.

Graves' orbitopathy should be managed according to the disease's severity and activity. Selenium supplementation should be considered in mild cases, while intravenous methylprednisolone is recommended in severe, active, and sight-threatening forms of ophthalmopathy [155]. Intravenous methylprednisolone is generally more effective and safer than oral prednisone [156] but should be administered in healthcare facilities after an accurate exclusion of possible contraindications (active tuberculosis, uncontrolled diabetes mellitus, viral hepatitis) [157]. Since the evident superiority of intravenous over oral glucocorticoids in patients with severe ophthalmopathy has been mostly observed in clinical activity score $>5$ [158], oral prednisone administered at home may be a good compromise in patients with moderately active orbitopathy. Orbital surgery should be deferred unless an urgent orbital decompression is mandatory [68]. Ocular manifestations of COVID-19 in patients with GD, including conjunctivitis, may lead to possible diagnostic delay of occurring Graves' orbitopathy manifestations. 


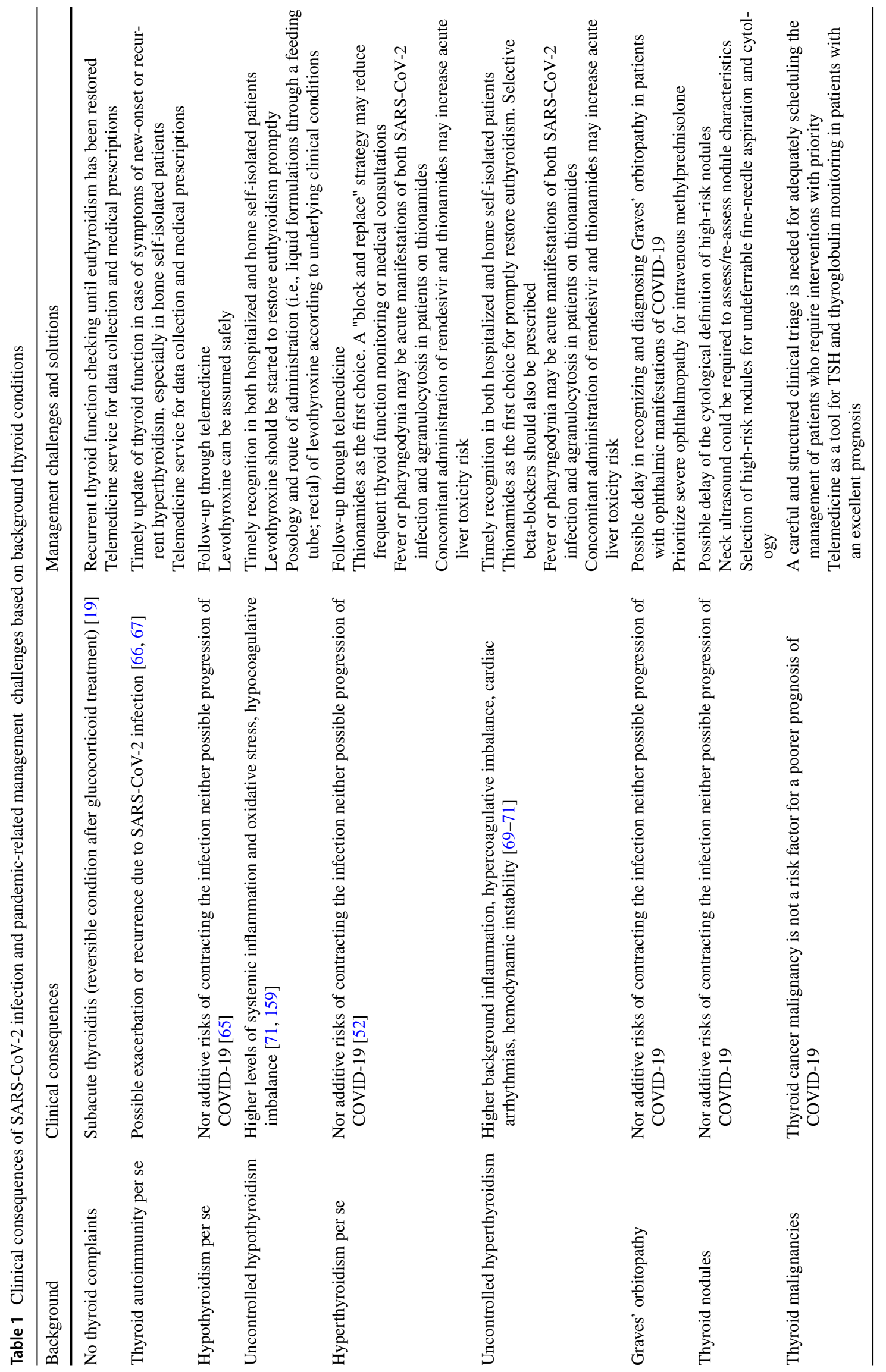




\section{Discussion and conclusions}

Thyroid dysfunction should be considered as a possible manifestation of COVID-19. Therefore, thyroid function assessment in patients with COVID-19 may be considered in the diagnostic work-up, particularly in hospitalized patients. In this cluster of patients, the low T3 syndrome prevalence is expected to be high and is related to the severity of COVID19. However, it is unclear whether T3 administration could improve prognosis in seriously ill patients, as the efficacy/ effectiveness and safety of the supplementation are currently under investigation. It should be considered that a concomitant administration of RDV and ATDs in hospitalized patients with hyperthyroidism may increase the risk of acute liver toxicity. Additionally, possible misinterpretation of thyroid dysfunction could result in patients assuming dexamethasone and heparin as these medications could alter thyroid hormone secretion and measurement acutely.

Asymptomatic or mildly affected COVID-19 patients may be managed at home. A thyroid function check should be carried out if required for treatment adjustment or in case of occurring symptoms of thyroid dysfunction.

Non-infected patients with any thyroid diseases should be punctually managed. In this historical moment, telemedicine may be a useful tool for managing patients necessitating frequent therapy adjustments, recurrent medical consultations, or for classifying and prioritizing patients requiring in-person visits unavoidably, such as thyroid aspiration for high-risk thyroid nodules, severe or active Graves' orbitopathy, management of new-onset or recurrent thyrotoxicosis, ongoing follow-up of progressing thyroid malignancy (Table 1).

Authors contribution GL and VT conceived the review. GL, ADT, VT, VAG performed database searching. GL and ADT drafted the manuscript. VT, EJ, VAG, GDP read the manuscript, provided feedback and criticisms. GL, ADT, EJ, VAG, GDP, EG, and VT accepted and approved the manuscript.

Funding Open access funding provided by Università degli Studi di Bari Aldo Moro within the CRUI-CARE Agreement.

\section{Declarations}

Conflict of interest All the authors declare that they have no conflict of interest.

Human and animals participants statements This article does not contain any studies with human participants or animals performed by any of the authors.

informed consent For this type of study formal consent is not required.
Open Access This article is licensed under a Creative Commons Attribution 4.0 International License, which permits use, sharing, adaptation, distribution and reproduction in any medium or format, as long as you give appropriate credit to the original author(s) and the source, provide a link to the Creative Commons licence, and indicate if changes were made. The images or other third party material in this article are included in the article's Creative Commons licence, unless indicated otherwise in a credit line to the material. If material is not included in the article's Creative Commons licence and your intended use is not permitted by statutory regulation or exceeds the permitted use, you will need to obtain permission directly from the copyright holder. To view a copy of this licence, visit http://creativecommons.org/licenses/by/4.0/.

\section{References}

1. Zhou P, Yang XL, Wang XG, Hu B, Zhang L, Zhang W, Si HR, Zhu Y, Li B, Huang CL, Chen HD, Chen J, Luo Y, Guo H, Jiang RD, Liu MQ, Chen Y, Shen XR, Wang X, Zheng XS, Zhao K, Chen QJ, Deng F, Liu LL, Yan B, Zhan FX, Wang YY, Xiao GF, Shi ZL (2020) A pneumonia outbreak associated with a new coronavirus of probable bat origin. Nature 579(7798):270-273. https://doi.org/10.1038/s41586-020-2012-7

2. Coronaviridae Study Group of the International Committee on Taxonomy of Viruses (2020) The species Severe acute respiratory syndrome-related coronavirus: classifying $2019-\mathrm{nCoV}$ and naming it SARS-CoV-2. Nat Microbiol 5(4), 536-44 https://doi. org/10.1038/s41564-020-0695-z

3. WHO Director-General's opening remarks at the media briefing on COVID-19 - 11 March 2020. https://www.who.int/dg/speec hes/detail/who-director-general-s-opening-remarks-at-the-media -briefing-on-covid-19-11-march-2020. Accessed April 11, 2020.

4. Shakiba M, Nazemipour M, Heidarzadeh A, Mansournia MA (2020) Prevalence of asymptomatic COVID-19 infection using a seroepidemiological survey. Epidemiol Infect: 1-7. https://doi. org/10.1017/S0950268820002745

5. Jeon J, Baruah G, Sarabadani S, Palanica A (2020) Identification of risk factors and symptoms of COVID-19: Analysis of biomedical literature and social media data. J Med Internet Res 22:e20509

6. Wolff D, Nee S, Hickey NS, Marschollek M (2020) Risk factors for Covid-19 severity and fatality: a structured literature review. Infection. https://doi.org/10.1007/s15010-020-01509-1

7. Onder G, Rezza G, Brusaferro S (2020) Case-fatality rate and characteristics of patients dying in relation to COVID-19 in Italy. JAMA 323:1775-1776. https://doi.org/10.1001/jama.2020.4683

8. Giagulli VA, Guastamacchia E, Magrone T, Jirillo E, Lisco G, De Pergola G, Triggiani V (2021) Worse progression of COVID19 in men: Is testosterone a key factor? Andrology 9(1):53-64. https://doi.org/10.1111/andr.12836

9. Lisco G, De Tullio A, Giagulli VA, Guastamacchia E, De Pergola G, Triggiani V (2020) Hypothesized mechanisms explaining poor prognosis in type 2 diabetes patients with COVID-19: a review. Endocrine 70(3):441-453. https://doi.org/10.1007/ s12020-020-02444-9

10. Temgoua MN, Endomba FT, Nkeck JR, Kenfack GU, Tochie JN, Essouma M (2020) Coronavirus disease 2019 (COVID-19) as a multi-systemic disease and its impact in low- and middle-income countries (LMICs). SN Compr Clin Med 20:1-11. https://doi. org/10.1007/s42399-020-00417-7

11. Pal R, Banerjee M (2020) COVID-19 and the endocrine system: exploring the unexplored. J Endocrinol Invest 43:1027-1031

12. Rhee EJ, Kim JH, Moon SJ, Lee WY (2020) Encountering COVID-19 as endocrinologists. Endocrinol Metab 35:197-205 
13. Mongioì LM et al (2020) Possible long-term endocrine-metabolic complications in COVID-19: lesson from the SARS model. Endocrine 68:467-470

14. Scappaticcio L, Pitoia F, Esposito K, Piccardo A, Trimboli P (2020) Impact of COVID-19 on the thyroid gland: an update. Rev Endocr Metab Disord 25:1-13. https://doi.org/10.1007/ s11154-020-09615-Z

15. Zou R, Wu C, Zhang S, Wang G, Zhang Q, Yu B, Wu Y, Dong H, Wu G, Wu S, Zhong Y (2020) Euthyroid Sick Syndrome in Patients With COVID-19. Front Endocrinol (Lausanne) 7(11): 566439. https://doi.org/10.3389/fendo.2020.566439

16. Lam SD, Bordin N, Waman VP, Scholes HM, Ashford P, Sen N, van Dorp L, Rauer C, Dawson NL, Pang CSM, Abbasian M, Sillitoe I, Edwards SJL, Fraternali F, Lees JG, Santini JM, Orengo CA (2020) SARS-CoV-2 spike protein predicted to form complexes with host receptor protein orthologues from a broad range of mammals. Sci Rep 10:16471. https://doi.org/10.1038/ s41598-020-71936-5

17. Han T, Kang J, Li G, Ge J, Gu J (2020) Analysis of 2019-nCoV receptor ACE2 expression in different tissues and its significance study. Ann Transl Med 8:1077-1077

18. Lazartigues E, Qadir MMF, Mauvais-Jarvis F (2020) Endocrine significance of SARS-CoV-2's reliance on ACE2. Endocrinology 161:1-7

19. Rotondi M et al (2020) Detection of SARS-COV-2 receptor ACE-2 mRNA in thyroid cells: a clue for COVID-19-related subacute thyroiditis. J Endocrinol Invest 6:1-6. https://doi.org/ 10.1007/s40618-020-01436-w

20. Gorini F, Bianchi F, Iervasi G (2020) Covid-19 and thyroid: Progress and prospects. Int J Environ Res Public Health 17:1-5

21. Luan J, Lu Y, Gao S, Zhang L (2020) A potential inhibitory role for integrin in the receptor targeting of SARS-CoV-2. J Infect 81:318-356

22. Sigrist CJ, Bridge A, Le Mercier P (2020) A potential role for integrins in host cell entry by SARS-CoV-2. Antiviral Res 177:104759

23. Davis PJ, Mousa SA, Lin H-Y (2020) Nongenomic actions of thyroid hormone: the integrin component. Physiol Rev 101:319352. https://doi.org/10.1152/physrev.00038.2019

24. Schmohl KA et al (2019) Integrin $\alpha v \beta 3$-mediated effects of thyroid hormones on mesenchymal stem cells in tumor angiogenesis. Thyroid 29:1843-1857

25. Davis PJ, Lin HY, Hercbergs A, Mousa SA (2020) Actions of 1-thyroxine (T4) and tetraiodothyroacetic acid (tetrac) on gene expression in thyroid cancer cells. Genes 11:1-9

26. Davis PJ, Lin HY, Hercbergs A, Keating KA, Mousa SA (2020) Coronaviruses and Integrin $\alpha v \beta 3$ : does thyroid hormone modify the relationship? Endocr Res 45:210-215

27. Swadling L, Maini MK (2020) T cells in COVID-19 — united in diversity. Nat Immunol 21:1307-1308

28. Muyayalo KP, Huang DH, Zhao SJ, Xie T, Mor G, Liao AH (2020) COVID-19 and Treg/Th17 imbalance: potential relationship to pregnancy outcomes. Am J Reprod Immunol 84(5): e13304. https://doi.org/10.1111/aji.13304

29. Moore JB, June CH (2020) Cytokine release syndrome in severe COVID-19. Science 368:473-474

30. Zhang $X$ et al (2020) Viral and host factors related to the clinical outcome of COVID-19. Nature 583:437-440

31. Lee JS, Park S, Jeong HW, Ahn JY, Choi SJ, Lee H, Choi B, Nam SK, Sa M, Kwon JS, Jeong SJ, Lee HK, Park SH, Park SH, Choi JY, Kim SH, Jung I, Shin EC (2020) Immunophenotyping of COVID-19 and influenza highlights the role of type I interferons in development of severe COVID-19. Sci Immunol 5(49): eabd1554. https://doi.org/10.1126/sciimmunol.abd1554

32. Lucas C, Wong P, Klein J, Castro TBR, Silva J, Sundaram M, Ellingson MK, Mao T, Oh JE, Israelow B, Takahashi T, Tokuyama
M, Lu P, Venkataraman A, Park A, Mohanty S, Wang H, Wyllie AL, Vogels CBF, Earnest R, Lapidus S, Ott IM, Moore AJ, Muenker MC, Fournier JB, Campbell M, Odio CD, CasanovasMassana A; Yale IMPACT Team, Herbst R, Shaw AC, Medzhitov R, Schulz WL, Grubaugh ND, Dela Cruz C, Farhadian S, Ko AI, Omer SB, Iwasaki A (2020) Longitudinal analyses reveal immunological misfiring in severe COVID-19. Nature 584: 463-469. https://doi.org/10.1038/s41586-020-2588-y

33. Mélo ML, Junior S, De J (2020) Review on therapeutic targets for COVID-19: insights from cytokine storm. Postgrad Med J. https://doi.org/10.1136/postgradmedj-2020

34. Costela-Ruiz VJ, Illescas-Montes R, Puerta-Puerta JM, Ruiz C, Melguizo-Rodríguez L (2020) SARS-CoV-2 infection: The role of cytokines in COVID-19 disease. Cytokine Growth Factor Rev 54:62-75

35. Morshed SA, Latif R, Davies TF (2012) Delineating the autoimmune mechanisms in Graves' disease. Immunol Res 54:191-203

36. Kawashima A et al (2013) Demonstration of innate immune responses in the thyroid gland: potential to sense danger and a possible trigger for autoimmune reactions. Thyroid 23:477-487

37. Hariyanto TI, Kurniawan A (2020) Thyroid disease is associated with severe coronavirus disease 2019 (COVID-19) infection. Diab Metab Synd Clin Res Rev 14:1429-1430

38. Agarwal S, Agarwal SK (2020) Endocrine changes in SARSCoV-2 patients and lessons from SARS-CoV. Postgrad Med J 96:412-416

39. Brancatella A, Ricci D, Viola N, Sgrò D, Santini F, Latrofa F (2020) Subacute thyroiditis after sars-COV-2 infection. J Clin Endocrinol Metab 105(7): dgaa276. https://doi.org/10.1210/clinem/dgaa276

40. Campos-Barrera E, Alvarez-Cisneros T, Davalos-Fuentes M (2020) Subacute thyroiditis associated with COVID-19. Case Rep Endocrinol:8891539

41. Mattar SAM, Koh SJQ, Rama Chandran S, Cherng BPZ (2020) Subacute thyroiditis associated with COVID-19. BMJ Case Rep 13:e237336

42. Asfuroglu Kalkan E, Ates I (2020) A case of subacute thyroiditis associated with Covid-19 infection. J Endocrinol Invest 43: $1173-1174$

43. Brancatella A et al (2020) Is subacute thyroiditis an underestimated manifestation of SARS-CoV-2 infection? Insights from a case series. J Clin Endocrinol Metab 105:1-5

44. Chakraborty U, Ghosh S, Chandra A, Ray AK (2020) Subacute thyroiditis as a presenting manifestation of COVID-19: a report of an exceedingly rare clinical entity. BMJ Case Rep 13(12):e239953. https://doi.org/10.1136/bcr-2020-239953

45. Ippolito S, Dentali F, Tanda ML (2020) SARS-CoV-2: a potential trigger for subacute thyroiditis? Insights from a case report. J Endocrinol Invest 43:1171-1172

46. Ruggeri RM, Campennì A, Siracusa M, Frazzetto G, Gullo D (2020) Subacute thyroiditis in a patient infected with SARSCOV-2: an endocrine complication linked to the COVID19 pandemic. Hormones 16:1-3. https://doi.org/10.1007/ s42000-020-00230-w

47. Tee LY, Hajanto S, Rosario BH (2020) COVID-19 complicated by Hashimoto's thyroiditis. Singapore Med J. https://doi.org/10. 11622/smedj.2020106

48. Dixit NM, Truong KP, Rabadia SV, Li D, Srivastava PK, Mosaferi T, Calfon Press MA, Donangelo I, Kelesidis T (2020) Sudden cardiac arrest in a patient with myxedema coma and COVID-19. J Endocr Soc 4(10):bvaa130. https://doi.org/10.1210/jendso/bvaa130

49. Caron P (2020) Thyroid disorders and SARS-CoV-2 infection: From pathophysiological mechanism to patient management. Ann Endocrinol (Paris) 81:507-510

50. Lui DTW, Lee CH, Chow WS, Lee ACH, Tam AR, Fong CHY, Law CY, Leung EKH, To KKW, Tan KCB, Woo YC, Lam CW, 
Hung IFN, Lam KSL (2020) Thyroid dysfunction in relation to immune profile, disease status and outcome in 191 patients with COVID-19. J Clin Endocrinol Metab. https://doi.org/10.1210/ clinem/dgaa 813

51. Chen M, Zhou W, Xu W (2020) Thyroid function analysis in 50 patients with COVID-19: a retrospective study. Thyroid. https:// doi.org/10.1089/thy.2020.0363

52. Muller I et al (2020) SARS-CoV-2-related atypical thyroiditis. Lancet Diab Endocrinol 8:739-741

53. Mendes D, Alves C, Silverio N, Batel MF (2019) Prevalence of undiagnosed hypothyroidism in europe: a systematic review and meta-analysis. Eur Thyroid J 8(3):130-143. https://doi.org/10. $1159 / 000499751$

54. Bjoro T, Holmen J, Krüger O, Midthjell K, Hunstad K, Schreiner T, Sandnes L, Brochmann H. Prevalence of thyroid disease, thyroid dysfunction and thyroid peroxidase antibodies in a large, unselected population. The Health Study of Nord-Trondelag (HUNT). Eur J Endocrinol 143(5): 639-47. https://doi.org/10. 1530/eje.0.1430639

55. Ehrenfeld M, Tincani A, Andreoli L, Cattalini M, Greenbaum A, Kanduc D, Alijotas-Reig J, Zinserling V, Semenova N, Amital H, Shoenfeld Y (2020) Covid-19 and autoimmunity. Autoimmun Rev 19(8):102597. https://doi.org/10.1016/j.autrev.2020.102597

56. Desailloud R, Hober D (2009) Viruses and thyroiditis: an update. Virol J 6:5. https://doi.org/10.1186/1743-422X-6-5

57. Somasundaram NP, et al (2020) The impact of SARS-Cov-2 virus infection on the endocrine system. Journal of the Endocrine Society 4: bvaa082

58. Almaghlouth NK et al (2020) Risk factors for mortality among patients with SARS-CoV-2 infection: a longitudinal observational study. J Med Virol. https://doi.org/10.1002/jmv.26560

59. Ulhaq ZS, Soraya GV (2020) Interleukin-6 as a potential biomarker of COVID-19 progression. Med Malad Infect 50:382-383

60. Henry BM, De Oliveira MHS, Benoit S, Plebani M, Lippi G (2020) Hematologic, biochemical and immune biomarker abnormalities associated with severe illness and mortality in coronavirus disease 2019 (COVID-19): a meta-analysis. Clin Chem Lab Med 58:1021-1028

61. Davies PH, Black EG, Sheppard MC, Franklyn JA (1996) Relation between serum interleukin- 6 and thyroid hormone concentrations in 270 hospital inpatients with non-thyroidal illness. Clin Endocrinol (Oxf) 44:199-205

62. Yamazaki K et al (1996) Interleukin-6 (IL-6) inhibits thyroid function in the presence of soluble IL-6 receptor in cultured human thyroid follicles. Endocrinology 137:4857-4863

63. Lania A et al (2020) Thyrotoxicosis in patients with COVID-19: The THYRCOV study. Eur J Endocrinol 183:381-387

64. Khoo B et al (2020) Thyroid function before, during and after COVID-19. J Clin Endocrinol Metab. https://doi.org/10.1210/ clinem/dgaa830

65. van Gerwen M. et al (2020) Outcomes of patients with hypothyroidism and COVID-19: a retrospective cohort study. Front Endocrinol (Lausanne) 11: 565. https://doi.org/10.3389/fendo.2020.00565

66. Mateu-Salat M, Urgell E, Chico A (2020) SARS-COV-2 as a trigger for autoimmune disease: report of two cases of Graves' disease after COVID-19. J Endocrinol Invest 43:1527-1528

67. Jiménez-Blanco S, Pla-Peris B, Marazuela M (2020) COVID19: a cause of recurrent Graves' hyperthyroidism? J Endocrinol Invest. https://doi.org/10.1007/s40618-020-01440-0

68. Bartalena L et al (2020) Management of Graves' hyperthyroidism and orbitopathy in time of COVID-19 pandemic. J Endocrinol Invest 43:1149-1151

69. Cappola AR, Desai AS, Medici M, Cooper LS, Egan D, Sopko G, Fishman GI, Goldman S, Cooper DS, Mora S, Kudenchuk PJ, Hollenberg AN, McDonald CL, Ladenson PW (2019) Thyroid and cardiovascular disease research agenda for enhancing knowledge, prevention, and treatment. Circulation. https://doi. org/10.1161/CIRCULATIONAHA.118.036859

70. Elnakish MT, Ahmed AA, Mohler PJ, Janssen PM (2015) Role of oxidative stress in thyroid hormone-induced cardiomyocyte hypertrophy and associated cardiac dysfunction: an undisclosed story. Oxid Med Cell Longev 2015:854265. https://doi.org/10. 1155/2015/854265

71. Elbers LPB, Fliers E, Cannegieter SC (2018) The influence of thyroid function on the coagulation system and its clinical consequences. J Thromb Haemost 16(4):634-645. https://doi.org/ $10.1111 /$ jth. 13970

72. Smulever A, Abelleira E, Bueno F, Pitoia F (2020) Thyroid cancer in the Era of COVID-19. Endocrine 70:1-5. https://doi.org/ 10.1007/s12020-020-02439-6

73. Gao W et al (2020) Thyroid hormone concentrations in severely or critically ill patients with COVID-19. J Endocrinol Invest. https://doi.org/10.1007/s40618-020-01460-w

74. Foks $M$ et al (2019) Thyroid hormones as potential prognostic factors in sepsis. Anaesthesiol Intens Therapy 51:205-209. https://doi.org/10.5114/ait.2019.86883

75. Chang X, Zhang S, Zhang M, Wang H, Fan C, Gu Y, Wei J, Qiu C (2018) Free triiodothyronine and global registry of acute coronary events risk score on predicting long-term major adverse cardiac events in STEMI patients undergoing primary PCI. Lipids Health Dis 17:234. https://doi.org/10.1186/s12944-018-0881-7

76. Triggiani V, Iacoviello M (2013) Thyroid disorders in chronic heart failure: from prognostic set-up to therapeutic management. Endoc Metab Immune Disord Targets 13: 22-37

77. Lisco G, De Tullio A, Iacoviello M, Triggiani V (2020) Congestive heart failure and thyroid dysfunction: the role of the low T3 syndrome and therapeutic aspects. Endocr Metab Immune Disord Drug Targets 20:646-653

78. Bartalena L, Bogazzi F, Brogioni S, Grasso L, Martino E (1998) Role of cytokines in the pathogenesis of the euthyroid sick syndrome. Eur J Endocrinol 138(6):603-614. https://doi. org/10.1530/eje.0.1380603

79. Moura Neto A, Zantut-Wittmann DE (2016) Abnormalities of thyroid hormone metabolism during systemic illness: the low $\mathrm{T} 3$ syndrome in different clinical settings. Int $\mathrm{J}$ Endocrinol 2016:2157583. https://doi.org/10.1155/2016/2157583

80. Iervasi G, Pingitore A, Landi P, Raciti M, Ripoli A, Scarlattini M, L'Abbate A, Donato L (2003) Low-T3 syndrome: a strong prognostic predictor of death in patients with heart disease. Circulation 107(5):708-713. https://doi.org/10.1161/01.cir. 0000048124.64204.3f

81. Perrotta C, Buldorini M, Assi E, Cazzato D, De Palma C, Clementi E, Cervia D (2014) The thyroid hormone triiodothyronine controls macrophage maturation and functions: protective role during inflammation. Am J Pathol 184:230-247. https://doi.org/10.1016/j.ajpath.2013.10.006

82. Contreras-Jurado C et al (2016) The thyroid hormone receptors inhibit hepatic interleukin-6 signaling during endotoxemia. Sci Rep 6:30990. https://doi.org/10.1038/srep30990

83. Zou R, Wu C, Zhang S, Wang G, Zhang Q, Yu B, Wu Y, Dong H, Wu G, Wu S, Zhong Y (2020) Euthyroid sick syndrome in patients With COVID-19. Front Endocrinol (Lausanne) 11: 566439. https://doi.org/10.3389/fendo.2020.566439

84. Xu J, Wang L (2019) Low T3 syndrome as a predictor of poor prognosis in patients with pyogenic liver abscess. Front Endocrinol (Lausanne) 10: 541. https://doi.org/10.3389/fendo.2019. 00541

85. Iacoviello M, et al (2019) Thyroid disorders and prognosis in chronic heart failure: a long-term follow-up study. Endocrine Metab Immune Disord Drug Targets 20: 437-445

86. Liu J, Wu X, Lu F, Zhao L, Shi L, Xu F (2016) Low T3 syndrome is a strong predictor of poor outcomes in patients with 
community-acquired pneumonia. Sci Rep 6:22271. https://doi. org/10.1038/srep22271

87. Kim JG, Shin H, Kim W, Lim TH, Jang B, Cho Y, Choi KS, Ahn C, Lee J, Na MK (2018) The value of decreased thyroid hormone for predicting mortality in adult septic patients: a systematic review and meta-analysis. Sci Rep Sep 8(1):14137. https://doi.org/10.1038/s41598-018-32543-7

88. Pantos C et al (2020) Triiodothyronine for the treatment of critically ill patients with COVID-19 infection: a structured summary of a study protocol for a randomised controlled trial. Trials 21:573

89. https://www.drugs.com/monograph/liothyronine.html. Accessed 01.19.2020

90. Wiersinga WM, Duntas L, Fadeyev V, Nygaard B, Vanderpump MP (2012) 2012 ETA guidelines: the use of L-T4 + L-T3 in the treatment of hypothyroidism. Eur Thyroid J 1(2):55-71. https://doi.org/10.1159/000339444

91. Kahaly GJ (2020) Management of graves thyroidal and extrathyroidal disease: an update. J Clin Endocrinol Metab 105:3704-3720. https://doi.org/10.1210/clinem/dgaa646

92. Ross DS, Burch HB, Cooper DS, Greenlee MC, Laurberg P, Maia AL, Rivkees SA, Samuels M, Sosa JA, Stan MN, Walter MA (2016) 2016 American thyroid association guidelines for diagnosis and management of hyperthyroidism and other causes of thyrotoxicosis. Thyroid 26(10):1343-1421. https:// doi.org/10.1089/thy.2016.0229

93. Boelaert $\mathrm{K}$ et al (2020) ENDOCRINOLOGY in the time of COVID-19: management of hyperthyroidism and hypothyroidism. Eur J Endocrinol 183:G33-G39

94. Vicente N, Cardoso L, Barros L, Carrilho F (2017) Antithyroid drug-induced agranulocytosis: state of the art on diagnosis and management. Drugs R D 17:91-96

95. Koehler VF et al (2020) Real-world efficacy and safety of cabozantinib and vandetanib in advanced medullary thyroid cancer. Thyroid. https://doi.org/10.1089/thy.2020.0206

96. Thornton K et al (2012) Vandetanib for the treatment of symptomatic or progressive medullary thyroid cancer in patients with unresectable locally advanced or metastatic disease: US Food and Drug Administration Drug approval summary. Clin Cancer Res 18:3722-3730

97. Fleeman $\mathrm{N}$ et al (2019) A systematic review of lenvatinib and sorafenib for treating progressive, locally advanced or metastatic, differentiated thyroid cancer after treatment with radioactive iodine. BMC Cancer 19:1209

98. Ferrari SM et al (2017) Sunitinib in the treatment of thyroid cancer. Curr Med Chem 26:963-972

99. Harris EJ et al (2018) Everolimus in anaplastic thyroid cancer: a case series. J Clin Oncol 36:e18112-e18112

100. Jayarangaiah A et al (2019) Therapeutic options for advanced thyroid cancer HHS public access metastatic. Int J Clin Endocrinol Metab 5:26-34

101. Weisberg E et al (2020) Repurposing of kinase inhibitors for treatment of COVID-19. Pharm Res 37:167. https://doi.org/10. 1007/s11095-020-02851-7

102. Derosa L, Melenotte C, Griscelli F et al (2020) The immunooncological challenge of COVID-19. Nat Cancer 1:946-964. https://doi.org/10.1038/s43018-020-00122-3

103. Wiersinga WJ, Rhodes A, Cheng AC, Peacock SJ, Prescott HC (2020) Pathophysiology, transmission, diagnosis, and treatment of Coronavirus Disease 2019 (COVID-19): a review. JAMA 324:782-793

104. https://www.covid19treatmentguidelines.nih.gov/overview/clini cal-spectrum/. Accessed 15.02.2021.

105. https://www.covid19treatmentguidelines.nih.gov/therapeuticmanagement/. Accessed 15.02.2021.
106. Medical Association A (2020) An EUA for bamlanivimab-A monoclonal Antibody for COVID-19. JAMA. https://doi.org/10. 1001/jama.2020.24415

107. https://www.covid19treatmentguidelines.nih.gov/statement-oncasirivimab-plus-imdevimab-eua/. Accessed 01.19.2021.

108. https://clinicaltrials.gov/ct2/show/NCT04535791? cond=NCT04 $535791 \&$ draw $=2 \&$ rank $=1$. Accessed 01.19.2021.

109. https://clinicaltrials.gov/ct2/show/NCT04366908?term=vitam in $+\mathrm{D} \&$ cond $=$ severe + covid $19 \&$ draw $=2 \&$ rank $=6$. Accessed 01.19 .2021

110. https://clinicaltrials.gov/ct2/show/NCT04264533?term=ascor bic + acid $\&$ cond $=$ severe + covid $19 \&$ draw $=2 \&$ rank $=2$. Accessed 01.19.2021.

111. https://clinicaltrials.gov/ct2/show/NCT04590274?term=hydro $\mathrm{xychloroquine} \&$ cond $=$ severe + covid $19 \& \mathrm{draw}=2 \& \operatorname{rank}=19$. Accessed 01.20.2021.

112. Vankadari N (2020) Arbidol: A potential antiviral drug for the treatment of SARS-CoV-2 by blocking trimerization of the spike glycoprotein. Int J Antimicrob Agents 56(2):105998. https://doi. org/10.1016/j.ijantimicag.2020.105998

113. Khalili JS, Zhu H, Mak NSA, Yan Y, Zhu Y (2020) Novel coronavirus treatment with ribavirin: Groundwork for an evaluation concerning COVID-19. J Med Virol 92(7):740-746. https://doi. org/10.1002/jmv.25798

114. Lamb YN (2020) Remdesivir: first approval. Drugs 80:1355-1363

115. Mody V, Ho J, Wills S, Mawri A, Lawson L, Ebert MCCJC, Fortin GM, Rayalam S, Taval S (202211) Identification of 3-chymotrypsin like protease (3CLPro) inhibitors as potential antiSARS-CoV-2 agents. Commun Biol 4(1): 93. https://doi.org/10. 1038/s42003-020-01577-x

116. Uzunova K, Filipova E, Pavlova V, Vekov T (2020) Insights into antiviral mechanisms of remdesivir, lopinavir/ritonavir and chloroquine/hydroxychloroquine affecting the new SARSCoV-2. Biomed Pharmacother 131:110668. https://doi.org/10. 1016/j.biopha.2020.110668

117. Chan HT, Chao CM, Lai CC (2020) Sofosbuvir/daclatasvir in the treatment of COVID-19 infection: a meta-analysis. J Infect. https://doi.org/10.1016/j.jinf.2020.12.021

118. Beigel JH et al (2020) Remdesivir for the treatment of covid19_final report. N Engl J Med. https://doi.org/10.1056/nejmo a2007764

119. Eslami G, Mousaviasl S, Radmanesh E, Jelvay S, Bitaraf S, Simmons B, Wentzel H, Hill A, Sadeghi A, Freeman J, Salmanzadeh S, Esmaeilian H, Mobarak M, Tabibi R, Jafari Kashi AH, Lotfi Z, Talebzadeh SM, Wickramatillake A, Momtazan M, Hajizadeh Farsani M, Marjani S, Mobarak S (2020) The impact of sofosbuvir/daclatasvir or ribavirin in patients with severe COVID-19. J Antimicrob Chemother 75(11):33663372. https://doi.org/10.1093/jac/dkaa331

120. Sahajpal R, Ahmed RA, Hughes CA, Foisy MM (2017) Probable interaction between levothyroxine and ritonavir: case report and literature review. Am J Health Syst Pharm 74(8):587-592. https://doi.org/10.2146/ajhp160200.PMID:28389458

121. Touzot M, Beller CL, Touzot F, Louet AL, Piketty C (2006) Dramatic interaction between levothyroxine and lopinavir/ ritonavir in a HIV-infected patient. AIDS 20(8):1210-1212. https://doi.org/10.1097/01.aids.0000226969.96880.3c

122. Piantanida E, Ippolito S, Gallo D, Masiello E, Premoli P, Cusini C, Rosetti S, Sabatino J, Segato S, Trimarchi F, Bartalena L, Tanda ML (2020) The interplay between thyroid and liver: implications for clinical practice. J Endocrinol Invest 43(7):885-899. https://doi.org/10.1007/s40618-020-01208-6

123. Mojtabavi H, Saghazadeh A, Rezaei N (2020) Interleukin-6 and severe COVID-19: a systematic review and meta-analysis. Eur Cytokine Netw 31:44-49 
124. Rubbert-Roth A, Furst DE, Nebesky JM, Jin A, Berber E (2018) A review of recent advances using tocilizumab in the treatment of rheumatic diseases. Rheumatol Ther 5:21-42

125. Tleyjeh IM, et al (2020) Efficacy and safety of tocilizumab in COVID-19 patients: a living systematic review and metaanalysis. Clin Microbiol Infect. https://doi.org/10.1016/j.cmi. 2020.10.036

126. Bousoik E, Montazeri Aliabadi H (2018) "Do we know jack" about JAK? A closer look at JAK/STAT signaling pathway. Front Oncol 8:287

127. Kubo $\mathrm{S}$ et al (2018) Janus kinase inhibitor baricitinib modulates human innate and adaptive immune system. Front Immunol 9:1510. https://doi.org/10.3389/fimmu.2018.01510

128. Kalil AC, et al (2020) Baricitinib plus remdesivir for hospitalized adults with covid-19. N Engl J Med: https://doi.org/10. 1056/NEJMoa2031994

129. Bieber T, et al (2020) Pooled safety analysis of baricitinib in adult patients with atopic dermatitis from 8 randomized clinical trials. J Eur Acad Dermatol Venereol. https://doi.org/10. $1111 /$ jdv. 16948

130. Bliddal S, Borresen SW, Feldt-Rasmussen U (2017) Thyroid autoimmunity and function after treatment with biological antirheumatic agents in rheumatoid arthritis. Front Endocrinol 8:179

131. Dexamethasone in Hospitalized Patients with Covid-19-preliminary report. N Engl J Med. https://doi.org/10.1056/nejmo a2021436

132. Prescott HC, Rice TW (2020) Corticosteroids in COVID19 ARDS: evidence and hope during the pandemic. JAMA 324:1292-1295

133. Burr WA et al (1976) Effect of a single dose of dexamethasone on serum concentrations of thyroid hormones. Lancet 308:58-61

134. Samuels MH (2000) Effects of variations in physiological cortisol levels on thyrotropin secretion in subjects with adrenal insufficiency: a clinical research center study1. J Clin Endocrinol Metab 85:1388-1393

135. Elston MS et al (2013) Duration of cortisol suppression following a single dose of dexamethasone in healthy volunteers: a randomised double-blind placebo-controlled trial. Anaesth Intens Care 41:596-601

136. Vigneri R et al (1975) Effect of dexamethasone on thyroid hormone response to TSH. Metabolism 24:1209-1213

137. Dumoulin SC, Perret BP, Bennet AP, Caron PJ (1995) Opposite effects of thyroid hormones on binding proteins for steroid hormones (sex hormone-binding globulin and corticosteroid-binding globulin) in humans. Eur J Endocrinol 132:594-598

138. Griffin EE, Miller LL (1974) Effects of hypophysectomy of liver donor on net synthesis of specific plasma proteins by the isolated perfused rat liver. Modulation by insulin, cortisol, triiodothyronine, and growth hormone. J Biol Chem 249: 5062-5069

139. Shabalin IG et al (2020) Molecular determinants of vascular transport of dexamethasone in COVID-19 therapy. IUCrJ 7:1048-1058

140. Wool GD, Miller JL (2020) The impact of COVID-19 disease on platelets and coagulation. Pathobiology. https://doi.org/10.1159/ 000512007

141. Lazzaroni MG et al (2020) Coagulation dysfunction in COVID19: the interplay between inflammation, viral infection and the coagulation system. Blood Rev. https://doi.org/10.1016/j.blre. 2020.100745

142. McBane RD et al (2020) Anticoagulation in COVID-19: a systematic review, meta-analysis and rapid guidance from the mayo clinic. Mayo Clin Proc 95:2467-2486

143. Buijsers B, Yanginlar C, Maciej-Hulme ML, de Mast Q, van der Vlag J (2020) Beneficial non-anticoagulant mechanisms underlying heparin treatment of COVID-19 patients. EBioMedicine 59:102969

144. Koulouri O, Moran C, Halsall D, Chatterjee K, Gurnell M (2013) Pitfalls in the measurement and interpretation of thyroid function tests. Best Pract Res Clin Endocrinol Metab 27:745-762

145. Vigliar E et al (2020) Cytology in the time of coronavirus disease (covid-19): an Italian perspective. J Clin Pathol. https://doi.org/ 10.1136/jclinpath-2020-206614

146. Venessa HMT, Matti G, Anthony G, Roderick CB, Bruce GR (2020) Thyroid cancer in the age of COVID-19. Endocr Relat Cancer 27:R407-R416

147. Moroti R, Badiu C (2020) Endocrine effects of COVID 19: Difficulties in the management of endocrine disorders from individual to societies. Acta Endocrinol 16:74-77

148. Shaha AR (2020) Thyroid surgery during COVID-19 pandemic: principles and philosophies. Head Neck 42:1322-1324

149. Lombardi CP et al (2020) Endocrine surgery during COVID-19 pandemic: do we need an update of indications in Italy? Endocrine 68:485-488

150. Jozaghi YJ, et al (2020) Endocrine surgery in the Coronavirus disease 2019 pandemic: surgical triage guidelines. Head Neck 42: 1325-1328. https://doi.org/10.1002/hed.26169.1325-1328

151. Baud $\mathrm{G}$ et al (2020) Endocrine surgery during and after the COVID-19 epidemic: expert guidelines from AFCE. J Visc Surg 157:S43-S49

152. Griffith ML, Bischoff LA, Baum HBA (2020) Approach to the patient with thyrotoxicosis using telemedicine. J Clin Endocrinol Metab 105:dgaa373. https://doi.org/10.1210/clinem/dgaa373

153. Kaur D, Galloway GK, Oyibo SO (2020) Patient satisfaction with the use of telemedicine in the management of hyperthyroidism. Cureus 12:e9859. https://doi.org/10.7759/cureus.9859

154. Freudenberg LS et al (2020) Global impact of COVID-19 on nuclear medicine departments: an international survey in April 2020. J Nucl Med 61:1278-1283

155. Bartalena L, Baldeschi L, Boboridis K, Eckstein A, Kahaly GJ, Marcocci C, Perros P, Salvi M, Wiersinga WM; European Group on Graves' Orbitopathy (EUGOGO) (2016) The 2016 European Thyroid Association/European Group on Graves' orbitopathy guidelines for the management of graves' orbitopathy. Eur Thyroid J 5(1): 9-26 https://doi.org/10.1159/000443828

156. Gao G, Dai J, Qian Y, Ma F (2014) Meta-analysis of methylprednisolone pulse therapy for Graves' ophthalmopathy. Clin Exp Ophthalmol 42(8):769-777. https://doi.org/10.1111/ceo.12317

157. Stiebel-Kalish H, Robenshtok E, Hasanreisoglu M, Ezrachi D, Shimon I, Leibovici L (2009) Treatment modalities for Graves' ophthalmopathy: systematic review and meta-analysis. J Clin Endocrinol Metab 94(8):2708-2716. https://doi.org/10.1210/jc. 2009-0376

158. Zang S, Ponto KA, Kahaly GJ (2011) Clinical review: Intravenous glucocorticoids for Graves' orbitopathy: efficacy and morbidity. J Clin Endocrinol Metab 96(2):320-332. https://doi.org/ 10.1210/jc.2010-1962

159. Mancini A, Di Segni C, Raimondo S, Olivieri G, Silvestrini A, Meucci E, Currò D (2016) Thyroid hormones, oxidative stress, and inflammation. Mediators Inflamm 2016:6757154. https://doi. org/10.1155/2016/6757154

Publisher's Note Springer Nature remains neutral with regard to jurisdictional claims in published maps and institutional affiliations. 


\section{Authors and Affiliations}

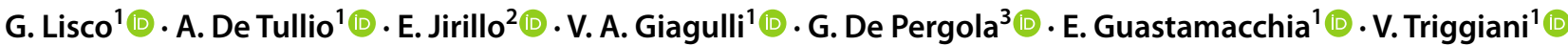

1 Interdisciplinary Department of Medicine, Section of Internal Medicine, Geriatrics, Endocrinology and Rare Diseases, School of Medicine, University of Bari "Aldo Moro", Bari, Apulia, Italy

2 Department of Basic Medical Science, Neuroscience and Sensory Organs, University of Bari Aldo Moro, Bari, Apulia, Italy
3 Department of Biomedical Sciences and Human Oncology, Section of Internal Medicine and Clinical Oncology, University of Bari Aldo Moro, Bari, Apulia, Italy 